\title{
Overlapping of irritable bowel syndrome with erosive esophagitis and the performance of Rome criteria in diagnosing IBS in a clinical setting
}

\author{
MAGDY EL-SALHY ${ }^{1-3}$, ODD HELGE GILJA ${ }^{2-4}$ and JAN GUNNAR HATLEBAKK ${ }^{2,3}$ \\ ${ }^{1}$ Section for Gastroenterology, Department of Medicine, Stord Hospital, 5416 Stord; \\ ${ }^{2}$ Department of Clinical Medicine, University of Bergen, 5007 Bergen; ${ }^{3}$ National Centre for Functional Gastrointestinal \\ Disorders, Department of Medicine; ${ }^{4}$ National Centre for Ultrasound in Gastroenterology, Department of Medicine, \\ Haukeland University Hospital, 5021 Bergen, Norway
}

Received August 26, 2018; Accepted May 15, 2019

DOI: $10.3892 / \mathrm{mmr} .2019 .10284$

\begin{abstract}
Irritable bowel syndrome (IBS) and gastroesophageal reflux disease (GERD) overlap. It is not clear whether GERD is caused by non-erosive esophagitis, or erosive esophagitis. The Rome criteria are not widely used for the diagnosis of IBS in the clinic. In total, 1,489 IBS patients without red flags were included in the present retrospective study. They comprised of 1,331 females and 158 males with a mean age of 51 years. The diagnosis of IBS was verified by endoscopic and histopathological examinations. Whereas erosive esophagitis occurred in $97 \%$ of patients, only $66 \%$ had GERD symptoms. Endoscopy and histopathological examinations revealed that $1.4 \%$ of the IBS patients with diarrhea as the predominant symptom had other organic gastrointestinal diseases: $0.3 \%$ with celiac disease, $0.2 \%$ with Crohn's disease, $0.07 \%$ with ulcerative colitis, $0.6 \%$ with microscopic colitis, and $0.2 \%$ with colon cancer. Applying the Rome III criteria produced a sensitivity of $100 \%$ [95\% confidence intervals $(\mathrm{CI})=99.8-100.0 \%$ ] a specificity of $98.7 \%(95 \% \mathrm{CI}=98.0-99.2 \%)$, a positive likelihood ratio of $76.9 \%$, and a negative likelihood ratio of $0 \%$. IBS is associated with erosive esophagitis. Applying Rome III criteria without red flags and history, was effective in diagnosing IBS. Celiac disease and microscopic colitis should be considered as alternative diagnoses.
\end{abstract}

\section{Introduction}

Irritable bowel syndrome (IBS) is a chronic recurrent gastrointestinal disorder $(1,2)$. IBS comprises two subsets: sporadic

Correspondence to: Professor Magdy El-Salhy, Section for Gastroenterology, Department of Medicine, Stord Hospital, Tysevegen 64, 5416 Stord, Norway

E-mail: magdy.el-salhy@helse-fonna.no

Key words: celiac disease, colon cancer, erosive esophagitis, irritable bowel disease, Rome criteria (nonspecific) and postinfectious (1,3). Sporadic IBS occurs in patients whose symptoms have been present for a long time without any association with gastrointestinal infections, while postinfectious IBS occurs in patients who experience the sudden onset of symptoms following a bout of gastroenteritis $(1,3)$. The absence of known anatomical, physiological, or biochemical defects in IBS means that an IBS diagnosis is reached by exclusion, whereby other gastrointestinal diseases that can cause symptoms similar to those of IBS are ruled out (1-4). Patients with IBS are therefore subjected to several expensive, uncomfortable, and painful examinations before a diagnosis can be made $(1,3,4)$.

IBS and gastroesophageal reflux disease (GERD) are common disorders in the population with prevalence of 11,2 , and $20 \%$, respectively (1-6). IBS and GERD overlap and meta-analysis showed that the prevalence of GERD in IBS patients is four-fold than in subjects without IBS (7-16). Twins studies revealed that genetic factors are important in both IBS and GERD (12). Moreover, IBS and GERD symptoms cluster in families (12). It is not clear whether this overlap occurs by chance as these disorders are common in the population or because they share a common pathophysiology (17). However, population-based studies showed that this overlap does not occur by chance (10). Whereas studies done on a large number of Asian IBS patients have shown that IBS overlaps with non-erosive esophagitis, but not with erosive esophagitis $(7,16,18)$, studies of a few European patients shown that erosive esophagitis overlaps with IBS and occurs in $80 \%$ of IBS patients $(8,19)$.

Symptom-based diagnosis criteria were introduced for establishing a method for the positive diagnosis of IBS, with the Rome IV criteria being the most recent (4,20-26). The main goals of symptom-based diagnosis are to avoid unnecessary expensive investigations and to facilitate the choice of treatment. Rome criteria have been used extensively as inclusion criteria in research studies as well as in clinical pharmacological trials. However, there are several reasons why these criteria are not used for the diagnosis of IBS in everyday clinical practice (4), such as clinicians being worried about missing organic diseases that mimic IBS, and the complexity of applying the criteria $(4,27)$. Furthermore, patients are often 
worried of having a serious or fatal disease, and are not reassured without undergoing tests and examinations to rule out such diseases (4).

The present retrospective study of a large number of European patients, which has not been done before, aimed at investigating the overlap of GERD with IBS and to determine whether IBS is associated with erosive or non-erosive esophagitis. Furthermore, it aimed at determining the probability of missing an organic disease when applying the Rome criteria.

\section{Materials and methods}

Patients. Patients referred to the Section for Gastroenterology, Stord Hospital from December 1, 2005 to December 31, 2016 who fulfilled the Rome III criteria for the diagnosis of IBS were considered for inclusion in the study (26). Patients aged between 18 and 85 years without alarm features (red flags), any organic gastrointestinal disease, or systemic disease were included in the study. The red flags include unintentional weight loss, rectal bleeding and/or anemia, signs of inflammation, family history of colorectal cancer, inflammatory bowel disease (IBD), and celiac disease (CD). Patients who had undergone any abdominal surgery were excluded, with the exception of appendectomy, Cesarean section, and hysterectomy.

In total, 1489 patients qualified for inclusion in the study. They comprised 1331 females and 158 males with a mean age of 51 years (range 18-82 years). Of these patients, 589 had diarrhea as the predominant symptom, (IBS-D), 496 had constipation as the predominant symptom, and 404 had a mixture of both diarrhea and constipation (IBS-M). All patients underwent a thorough medical history-taking and they were asked particularly about GERD symptoms. Totally, 496 patients took proton pump inhibitor (PPI) on demand. They were further investigated by blood tests, and had normal findings for the full blood count, inflammatory markers, electrolytes, folic acid, vitamin B12, and kidney, liver, and thyroid function tests.

The Regional Committee for Medical and Health Research Ethics West, Bergen, Norway waived the need for ethics approval and the need to obtain consent for the collection, analysis and publication of the retrospectively obtained and anonymized data for this non-interventional study.

Endoscopy. All patients underwent standard gastroscopy and colonoscopy, which were performed by an experienced single gastroenterologist (MES). Gastroscopy was performed after an overnight fast, during which four biopsy samples were taken from the duodenum distal to the papilla of Vater. Patients used PPI were asked not to take this medication one week prior to gastroscopy. A routine colonoscopy was performed, during which two biopsies were taken from each of the cecum, ascending colon, transverse colon, descending colon, and sigmoid colon. Further biopsy samples were taken from pathological findings when they were observed. The biopsy samples were fixed overnight in $4 \%$ buffered paraformaldehyde.

Histopathology and immunohistochemistry. The biopsy samples obtained from the duodenum and colon were processed to paraffin blocks that were cut into $5-\mu \mathrm{m}$-thick sections. The sections were stained with hematoxylin and eosin and immunostained using the ultraView Universal DAB Detection kit (v.1.02.0018; Venata Medical Systems, Basel, Switzerland) and the BenchMark Ultra IHC/ISH staining module (Venata Medical Systems). They were incubated with the primary antibody for $35 \mathrm{~min}$ at $37^{\circ} \mathrm{C}$. The primary antibodies used were monoclonal mouse antihuman leukocytes CD45 (cat. no. IS751; Dako, Glostrup, Denmark) and monoclonal antibodies to collagen type III (cat. no. P02461; Acris, Herford, Germany). CD45 is considered a common leukocyte antigen and is expressed exclusively on cells of the hematopoietic system and their progenitors. The sections were examined for the possible occurrence of CD using Marsh's modified classification. Lymphocytic colitis was diagnosed in the presence of an increase in intraepithelial lymphocytes (>15 lymphocytes/100 epithelial cells), surface epithelial damage, increased lamina propria plasma cells, and absent or minimal crypt architectural distribution (28). Collagenous colitis was diagnosed when there was an increase or irregularity in subepithelial collagen $(>10 \mu \mathrm{m})$ as well as the other inflammatory changes seen in lymphocytic colitis (28).

Statistical analysis. The difference between IBS subtypes in the incidence of GERD symptoms and erosive esophagitis were performed by Chi-square test. Fisher's exact test was used for statistical analysis, and the sensitivity, specificity, positive and negative predictive values, and likelihood ratios when applying Rome III criteria were calculated. The positive $(+\mathrm{LR})$ and negative (-LR) likelihood ratios are calculated as $+\mathrm{LR}=$ sensitivity/1-specificity) and $-\mathrm{LR}=$ specificity/(1-sensitivity): $+\mathrm{LR}>10$ is useful for ruling IBS in and $-\mathrm{LR}<0.1$ is useful for ruling IBS out (29). These analyses were performed using GraphPad Prism (v.7; La Jolla, CA, USA).

\section{Results}

Endoscopy and histopathology. Of the 1489 IBS patients, 983 (66\%) complained, in addition to IBS symptoms, of heartburn, acid regurgitation, nausea, and globus (Table I). The incidence of GERD symptom was higher in IBS-C and IBS-M than that in IBS-D (Table II).

Gastroscopy revealed that of the 1489 IBS patients, 1449 have erosive esophagitis (97\%), 25 had duodenal ulcers $(1.7 \%)$, and 9 had gastric ulcers $(0.6 \%)$; the other patients had normal endoscopy findings. Of the patients with erosive esophagitis 1128 (78\%) esophagitis grade A, 298 (20.4\%) grade B and $23(1.6 \%)$ grade C according to Los Angeles classification $(30,31)$. In IBS-D $575(97 \%)$ patients had erosive esophagitis (97\%). There was no difference in the incidence of erosive esophagitis between IBS-D and IBS-C $(\mathrm{P}=0.4)$, between IBS-D and IBS-M $(\mathrm{P}=0.9)$ or between IBS-C and IBS-M ( $\mathrm{P}=0.5)$ (Table II).

The histopathological examinations of the duodenal biopsies showed that 15 IBS-D patients had CD of Marsh type 1, 1 patient had CD of Marsh type 2, and 2 patients had CD of Marsh type $3 \mathrm{~b}$. The 15 patients with $\mathrm{CD}$ of Marsh type 1 underwent another gastroscopy after 3-6 months, and new duodenal biopsy samples were taken and re-examined histopathologically. Moreover, serological tests for tissue transglutaminase antibodies (anti-tTG) IgA were applied to these patients. Only 2 of the 15 original patients with Marsh type $1 \mathrm{CD}$ also showed Marsh type 1 CD in the second duodenal biopsy samples, and positivity for anti-tTG IgA (Fig. 1). The other 13 patients had 
Table I. Gastroesophageal reflux disease symptoms in the IBS patients studied.

\begin{tabular}{lccrr}
\hline & \multicolumn{3}{c}{ Symptom observed, $\mathrm{n}$} \\
\cline { 2 - 5 } Group & Heartburn & Regurgitation & Nausea & Globus \\
\hline All IBS patients & 802 & 798 & 345 & 10 \\
IBS-D & 205 & 198 & 2 & 1 \\
IBS-C & 341 & 342 & 56 & 14 \\
IBS-M & 310 & 298 & 1 & 0 \\
\hline
\end{tabular}

IBS, irritable bowel syndrome; IBS-D, IBS with diarrhea as the predominant symptom; IBS-M, IBS with a mixture of diarrhea and constipation; IBS-C, IBS with constipation as the predominant symptom.

normal histology findings and were negative for anti-tTG IgA. These five patients with CD were all females (aged 20, 24, 36, 38, and 60 years) and belonging to the IBS-D subtype (Table III).

Colonoscopy examinations showed that the ileum, colon, and rectum were endoscopically normal in all of the IBS patients except for seven of those with IBS-D (Table III). Three of these patients had scattered aphthoid ulcers in the mucosa of the terminal ileum (Fig. 2). Histopathological examinations confirmed the diagnosis of Crohn's disease. These patients were all females, and were aged 28, 32, and 59 years. The fourth patient had erythematous friable mucosa with loss of the normal vascular pattern, with this lesion including $10 \mathrm{~cm}$ of the sigmoid colon and the entire rectum (Fig. 3). Histopathological examinations of the biopsy samples taken from the lesions revealed ulcerative colitis. This patient was a female aged 57 years. The remaining three patients each had a tumor in the sigmoid colon (Fig. 4), which histopathological examinations of the biopsy samples revealed to be adenocarcinomas. These patients were a female aged 58 years and two males aged 52 and 56 years.

Histopathological examinations of the macroscopically normal colon showed that two of the IBS-D patients had collagenous colitis (Fig. 5) and seven IBS-D patients had lymphocytic colitis. The two patients with collagenous colitis were males, aged 36 and 42 years, while those with lymphocytic colitis comprised five females and two males aged 24, 27, $35,36,42,79$, and 82 years.

Applying the Rome III criteria produced a sensitivity of $100 \%$ (95\% confidence interval $[\mathrm{CI}]=99.8-100.0 \%$ ), a specificity of $98.7 \%$ (95\% CI=98.0-99.2), a positive predictive value of $98.7 \%(95 \% \mathrm{CI}=98.8-99.2 \%)$, and a negative predictive value of $100 \%$ (95\% CI=99.7-100.0\%). The LR was $74.4 \%$. The calculated $+\mathrm{LR}$ at 76.9 and $-\mathrm{LR}$ at $0 \%$.

Clinical data. The five patients with CD adhered to gluten-free diet, but they still suffered from diarrhea, recurrent abdominal pain, and abdominal bloating. The histopathology findings for the duodenal biopsy samples taken during a new gastroscopy were normal.

The patients with IBD showed IBS symptoms during the remission period. Similarly, those patients with colon cancer suffered from IBS symptoms after receiving the surgical treatment for their carcinoma. All patients with microscopic colitis (MC) became symptom-free after receiving adequate treatment.
Table II. Prevalence of GERD and erosive esophagitis in the total number of IBS patients studied and in the IBS sub-types.

\begin{tabular}{lcc}
\hline Group & $\begin{array}{c}\text { Patients with } \\
\text { GERD, n (\%) }\end{array}$ & $\begin{array}{r}\text { Patients with erosive } \\
\text { esophagitis, n (\%) }\end{array}$ \\
\hline IBS patients total & $983(66)$ & $14,449(97)$ \\
IBS-D patients & $589(55)$ & $575(97)$ \\
IBS-C patients & $342(69)^{\mathrm{a}}$ & $480(97)$ \\
IBS-M patients & $320(79)^{\mathrm{a}}$ & $394(97)$ \\
\hline
\end{tabular}

${ }^{\mathrm{a}} \mathrm{P}<0.0001$ vs. IBS-D. GERD, gastroesophageal reflux disease; IBS, irritable bowel syndrome; IBS-D, IBS with diarrhea as the predominant symptom; IBS-M, IBS with a mixture of diarrhea and constipation; IBS-C, IBS with constipation as the predominant symptom.

\section{Discussion}

Several factors contribute to the high prevalence of esophagitis such as smoking, overweight, coffee drinking. However, the present study aimed at investigating the occurrence of esophagitis in an IBS population not in general population. We assumed that the occurrence of these factors in the IBS sample studied is the same as in the background population.

The present investigation is the first study of a large cohort of European IBS patients to establish the correlation between esophagitis and IBS. In the cohort of IBS patients studied here, the prevalence of GERD symptoms was $66 \%$, which agrees well with the meta-analysis results reported earlier (17). The present study showed further that the prevalence of GERD symptoms is higher in IBS-C and IBS-M than that in IBS-D. Although $97 \%$ of the IBS patients in this study had erosive esophagitis, only $66 \%$ complained of GERD symptoms. This may due to that 496 of the patients (33\%) took PPI on demand. However, 506 patients (34\%) of the IBS patients included in the study were asymptomatic despite the esophageal lesions. It is also probably that IBS symptoms over shadowed the GERD symptoms in the asymptomatic patients. It is noteworthy that most of the erosive esophagitis in IBS patients were of grade A. Esophagitis grade A showed a high interobserver variation $(32,33)$. However, in this study the endoscopic diagnosis was made by an experienced single gastroenterologist. 


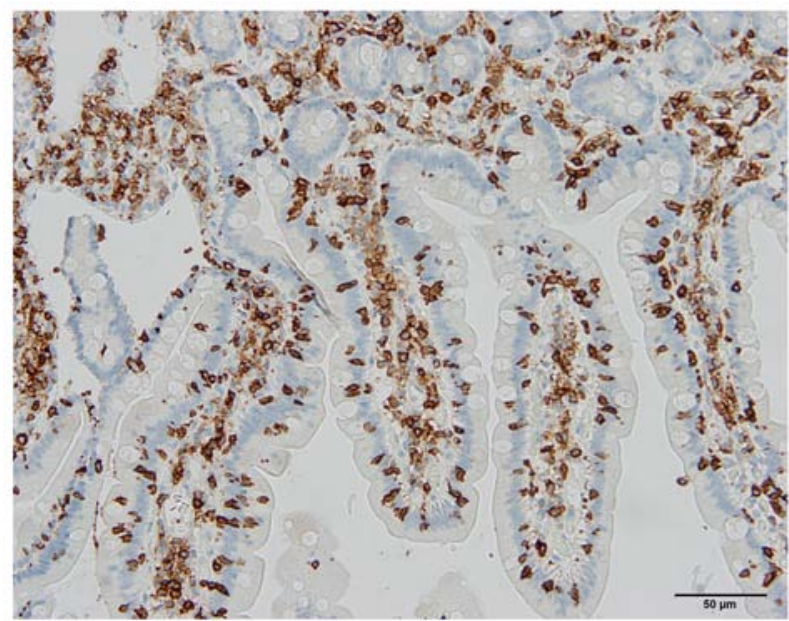

Figure 1. Photomicrograph of the duodenum of a 24-year-old female diagnosed with irritable bowel syndrome based on Rome III criteria, who was found to suffer from celiac disease of Marsh type 1. The section was immunostained for CD45, which is a common leukocyte antigen and is expressed exclusively on cells of the hematopoietic system and their progenitors. Scale bar, $50 \mu \mathrm{m}$.

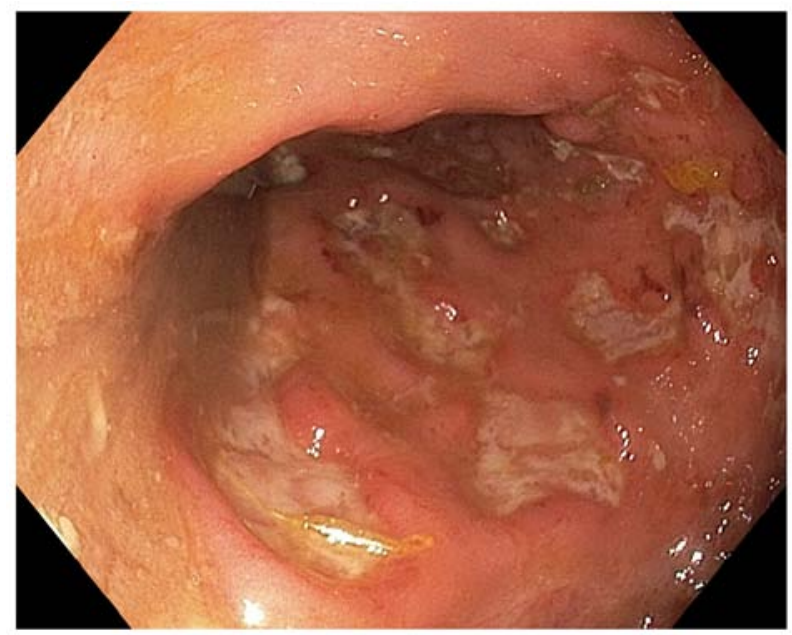

Figure 2. Endoscopic appearance of the terminal ileum with aphthoid ulcers in a 32-year-old female who fulfilled the Rome III criteria. A histopathological examination confirmed the diagnosis of Crohn's disease.

Whereas there is a general agreement that IBS overlaps with GERD, it is controversial as whether IBS is associated with non-erosive esophagitis or with erosive esophagitis. It is noteworthy that studies done on a few IBS patients in the Western world, showed an association between erosive esophagitis and IBS $(8,19)$. In contrast, studies done on Asian IBS patients showed an association between IBS and non-erosive esophagitis, but not with erosive esophagitis $(7,18)$. IBS in Asia differs considerably from that in the Western world (USA and Europe). This difference includes the prevalence, gender predominance, clinical presentation, and probably the pathophysiology (34-58). The difference between patients with IBS in the Western world and those in Asia may account for the discrepancy in the association of IBS with non-erosive and erosive esophagitis.

The Rome symptom-based criteria for the diagnosis of IBS have been validated in several comprehensive reviews 


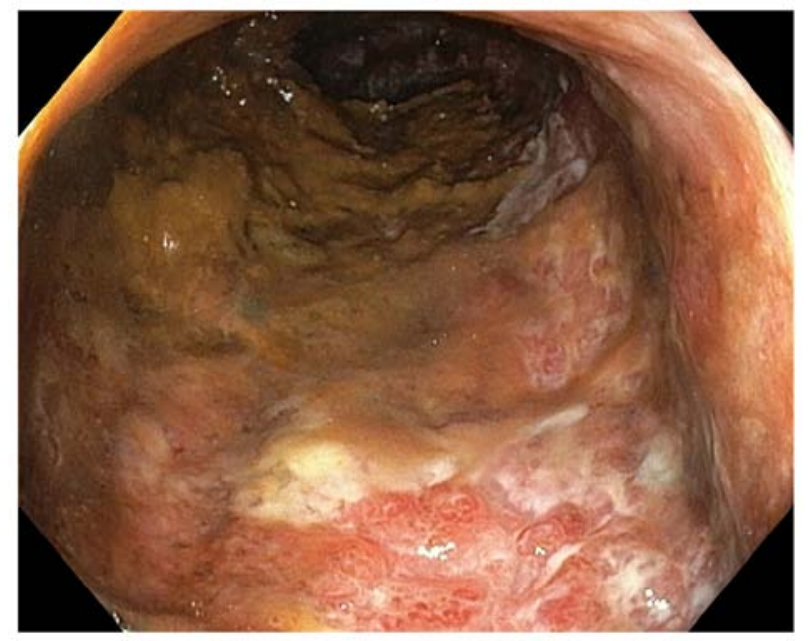

Figure 3. Photograph of the sigmoid colon taken during the colonoscopy of a 57-year-old female diagnosed with IBS based on Rome III criteria. A histopathological examination confirmed the diagnosis of ulcerative colitis.

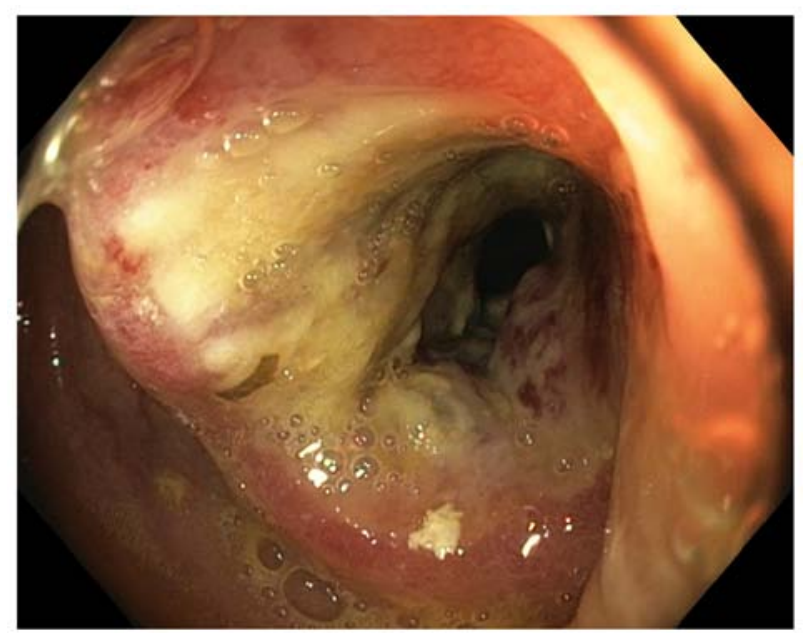

Figure 4. A tumor in the sigmoid colon observed during the colonoscopy of a 56-year-old male diagnosed with irritable bowel syndrome based on Rome III criteria. A histopathological examination showed that the tumor was an adenocarcinoma.

and found to have a modest specificity and reasonable sensitivity (27,59-61). The Rome criteria were recently validated by latent class analysis in Canadian and British cohorts comprising 1981 and 360 IBS patients, respectively (62). In this model, the sensitivity in the Canadian and British cohorts were 44.7, and $52.5 \%$, respectively; the corresponding values for specificity were 85.3 and $84.3 \%$ (62), while the +LRs were 3.03 and 3.35 , and the -LRs were 0.65 and 0.56 (62). In the present cohort of about 1500 Norwegian IBS patients, the application of Rome III criteria including red flags combined with medical history, normal physical examination, and normal blood tests yielded sensitivity, specificity, +LR, and -LR values of 100 , 98.7, 76.9, and 0\%, respectively. The Kruis scoring system for the diagnosis of IBS incorporated symptoms with negative physical findings and normal laboratory tests (63). Moreover, combining Rome criteria with red flags, medical history, and limited diagnostic tests has previously been shown to improve the diagnostic performance $(29,59)$.

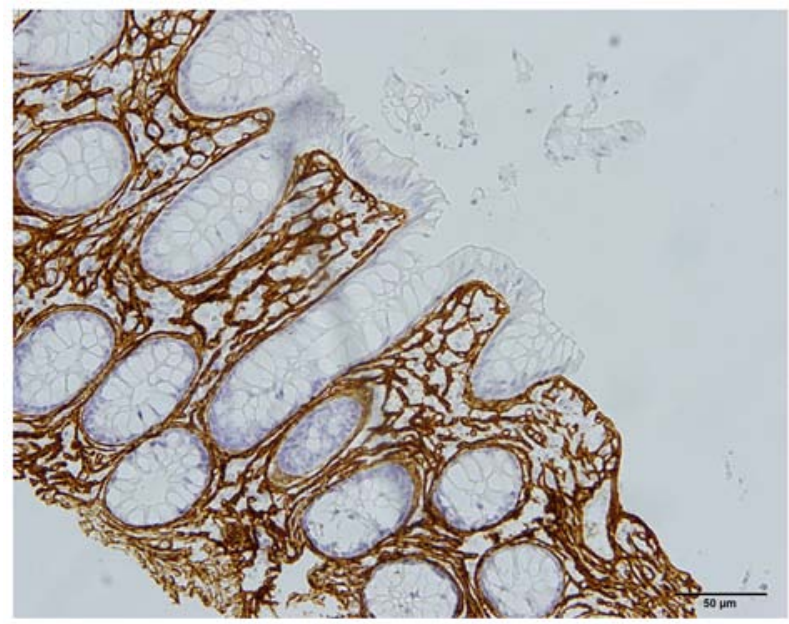

Figure 5. Photomicrograph taken from the colon of a 42-year-old male who fulfilled the Rome III criteria. A histopathological examination revealed the presence of collagenous colitis. The section showed positive immunostaining for collagen III. Scale bar, $50 \mu \mathrm{m}$.

The gastrointestinal organic diseases whose symptoms overlap those of IBS and which physicians are concerned about missing when using symptom-based criteria are colorectal cancer, CD, IBD, MC, bacterial overgrowth, and bile acid malabsorption (4). It has been reported that $0.02-0.5 \%$ of IBS patients diagnosed using symptom-based criteria had colorectal cancer, while $0.04-4.7 \%$ had CD, 0.4-1.9\% had IBD, and $0.7-1.5 \%$ had MC $(1,3,4,64-83)$. This means that $1.2-8.6 \%$ of patients suffering from other organic diseases were misdiagnosed with IBS when applying symptom-based criteria, which justifies the concerns of clinicians. In the present study, endoscopic and histopathological examinations of patients diagnosed using Rome III criteria revealed that $1.4 \%$ had another gastrointestinal organic disease: $0.2,0.3,0.3$, and $0.6 \%$ had colorectal cancer, $\mathrm{CD}, \mathrm{IBD}$, and $\mathrm{MC}$, respectively. It is noteworthy that all of these patients had the IBS-D subtype. Would these patients actually be missed in a clinical setting? The patients with colorectal cancer detected in this study were suffering from IBS, and the IBS symptoms were the reason for visiting a doctor; that is, the colon cancer was found incidentally. All three patients were older than 50 years. The American College of Gastroenterology and the British Society of Gastroenterology recommend colonoscopies for individuals aged $>50$ years who have IBS symptoms $(74,84)$. The CD and IBD patients in the present study appeared to have IBS in addition to their organic diseases. Typically 20-37\% of CD patients exhibit IBS symptoms despite adhering to a gluten-free diet (85) and are believed to have IBS in addition to CD (85). The symptoms in these patients are triggered by the ingestion of wheat and wheat products, and it is difficult to conclude whether this is caused by gluten or by the long-sugar-polymer fructans in wheat (86). This led to the British Society of Gastroenterology recommending excluding $\mathrm{CD}$ in all patients referred with IBS, and to the American College of Gastroenterology advising excluding CD in patients with IBS-D or IBS-M $(74,84)$. Typically $32-39 \%$ of patients with ulcerative colitis and $42-60 \%$ of patients with Crohn's disease suffer from IBS when they are in remission (3,76-81). The patients with IBD in the present study 
also suffered from IBS, and it just happened that they had active disease when the colonoscopies were performed. None of these patients would have been misdiagnosed in a clinical setting. In contrast, patients with MC could be misdiagnosed, and this group of patients should be kept in mind when symptom-based criteria are used in the diagnosis of IBS, especially in IBS patients with diarrhea as the predominant symptom.

It is usual in clinical practice for some IBS patients to seek health care not because of the symptoms but due to concerns about possible serious or fatal underlying conditions $(87,88)$. Whereas negative gastroscopy findings have been reported to reassure patients with functional dyspepsia and improve their quality of life, this did not occur for colonoscopy normal findings in patients with IBS (25). However, the health-care provider is compelled to accommodate patients who desire endoscopic examinations for reassurance.

In conclusion, Rome III symptom-based criteria with red flags, history, negative physical findings, and normal blood tests perform well in diagnosing IBS. As when applying other diagnostic methods in the clinic, the overall view of the patient should also be considered. The Rome Foundation is developing methods to facilitate the use of Rome criteria in everyday clinic practices (27). Patients who need reassurance by performing further examinations should be accommodated.

Because of the strong association of GERD with IBS, it has been recommended that physicians who encountered IBS patients should screen them routinely for the co-existence of GERD (17). The findings of high prevalence of erosive esophagitis in IBS patients found here support this recommendation.

\section{Acknowledgements}

Not applicable.

\section{Funding}

The present study was supported by grants from Helse-Vest (grant no. 912234), and Helse-Fonna (grant no. 40415).

\section{Availability of data and materials}

The datasets used and/or analyzed during the present study are available from the corresponding author on reasonable request.

\section{Authors' contributions}

MES designed the study, recruited the patients, obtained the medical histories, and physically examined and performed gastroscopies and colonoscopies on the IBS patients. MES also further analyzed the data and drafted the manuscript. OHG and JGH contributed to the design of the study, analyzed the data, and reviewed the manuscript.

\section{Ethics approval and consent to participate}

The Regional Committee for Medical and Health Research Ethics West (Bergen, Norway) waived the need for ethical approval and the need to obtain consent for the collection, analysis and publication of the retrospectively obtained and anonymized data for this non-interventional study.

\section{Patient consent for publication}

Not applicable.

\section{Competing interests}

The authors declare that they have no competing interests.

\section{References}

1. El-Salhy M: Irritable bowel syndrome: Diagnosis and pathogenesis. World J Gastroenterol 18: 5151-5163, 2012.

2. El-Salhy M: Recent developments in the pathophysiology of irritable bowel syndrome. World J Gastroenterol 21: 7621-7636, 2015.

3. El-Salhy M, Hatlebakk JG, Gilja $\mathrm{OH}$ and Hausken T: Irritable bowel syndrome: Recent developments in diagnosis, pathophysiology, and treatment. Expert Rev Gastroenterol Hepatol 8: 435-443, 2014

4. El-Salhy M: Recent advances in the diagnosis of irritable bowel syndrome. Expert Rev Gastroenterol Hepatol 9: 1161-1174, 2015.

5. Locke GR III, Talley NJ, Fett SL, Zinsmeister AR and Melton LJ III: Prevalence and clinical spectrum of gastroesophageal reflux: A population-based study in Olmsted County, Minnesota. Gastroenterology 112: 1448-1456, 1997.

6. Canavan C, West J and Card T: The epidemiology of irritable bowel syndrome. Clin Epidemiol 6: 71-80, 2014.

7. Nam SY, Ryu KH and Park BJ: Irritable bowel syndrome is associated with gastroesophageal reflux symptom but not erosive esophagitis. J Neurogastroenterol Motil 19: 521-531, 2013.

8. Smart HL, Nicholson DA and Atkinson M: Gastro-oesophageal reflux in the irritable bowel syndrome. Gut 27: 1127-1131, 1986.

9. Lee SY, Lee KJ, Kim SJ and Cho SW: Prevalence and risk factors for overlaps between gastroesophageal reflux disease, dyspepsia, and irritable bowel syndrome: A population-based study. Digestion 79: 196-201, 2009.

10. Jung HK, Halder S, McNally M, Locke GR III, Schleck CD, Zinsmeister AR and Talley NJ Overlap of gastro-oesophageal reflux disease and irritable bowel syndrome: Prevalence and risk factors in the general population. Aliment Pharmacol Ther 26: 453-461, 2007.

11. Talley NJ: Overlapping abdominal symptoms: Why do GERD and IBS often coexist? Drugs Today (Barc) 42 (Suppl B): S3-S8, 2006.

12. Lembo A, Zaman M, Jones $M$ and Talley NJ: Influence of genetics on irritable bowel syndrome, gastro-oesophageal reflux and dyspepsia: A twin study. Aliment Pharmacol Ther 25: 1343-1350, 2007.

13. Cheung TK, Lam KF, Hu WH, Lam CL, Wong WM, Hui WM, Lai KC, Lam SK and Wong BC: Positive association between gastro-oesophageal reflux disease and irritable bowel syndrome in a Chinese population. Aliment Pharmacol Ther 25: 1099-1104, 2007.

14. Wu JC, Cheung CM, Wong VW and Sung JJ: Distinct clinical characteristics between patients with nonerosive reflux disease and those with reflux esophagitis. Clin Gastroenterol Hepatol 5: 690-695, 2007

15. Lovell RM and Ford AC: Global prevalence of and risk factors for irritable bowel syndrome: A meta-analysis. Clin Gastroenterol Hepatol 10: 712-721 e4, 2012.

16. Noh YW, Jung HK, Kim SE and Jung SA: Overlap of erosive and non-erosive Reflux diseases with functional gastrointestinal disorders according to Rome III criteria. J Neurogastroenterol Motil 16: 148-156, 2010.

17. Lovell RM and Ford AC: Prevalence of gastro-esophageal reflux-type symptoms in individuals with irritable bowel syndrome in the community: A meta-analysis. Am J Gastroenterol 107: 1793-1802, 2012.

18. Zhao Y, Zou D, Wang R, Ma X, Yan X, Man X, Gao L, Fang J, Yan H, Kang X, et al: Dyspepsia and irritable bowel syndrome in China: A population-based endoscopy study of prevalence and impact. Aliment Pharmacol Ther 32: 562-572, 2010.

19. Neumann H, Monkemuller K, Kandulski A and Malfertheiner P: Dyspepsia and IBS symptoms in patients with NERD, ERD and Barrett's esophagus. Dig Dis 26: 243-247, 2008.

20. Schmulson MJ and Drossman DA: What is new in Rome IV. J Neurogastroenterol Motil 23: 151-163, 2017. 
21. Manning AP, Thompson WG, Heaton KW and Morris AF: Towards positive diagnosis of the irritable bowel. Br Med J 2: 653-654, 1978.

22. Jellema P, van der Windt DA, Schellevis FG and van der Horst HE: Systematic review: Accuracy of symptom-based criteria for diagnosis of irritable bowel syndrome in primary care. Aliment Pharmacol Ther 30: 695-706, 2009.

23. Ford AC, Talley NJ, Veldhuyzen van Zanten SJ, Vakil NB, Simel DL and Moayyedi P: Will the history and physical examination help establish that irritable bowel syndrome is causing this patient's lower gastrointestinal tract symptoms? JAMA 300 1793-1805, 2008.

24. Drossman DA: The functional gastrointestinal disorders and the Rome II process. Gut 45 (Suppl 2): II1-II5, 1999.

25. Lin OS: Colonoscopy in irritable bowel syndrome: Whom are we reassuring? Gastrointest Endosc 62: 900-902, 2005.

26. Longstreth GF, Thompson WG, Chey WD, Houghton LA, Mearin F and Spiller RC: Functional bowel disorders. Gastroenterology 130: 1480-1491, 2006.

27. Whitehead WE, Palsson OS and Simrén M: Irritable bowel syndrome: What do the new Rome IV diagnostic guidelines mean for patient management? Expert Rev Gastroenterol Hepatol 11: 281-283, 2017.

28. Pardi DS, Smyrk TC, Tremaine WJ and Sandborn WJ: Microscopic colitis: A review. Am J Gastroenterol 97: 794-802, 2002.

29. Sood R, Camilleri M, Gracie DJ, Gold MJ, To N, Law GR and Ford AC: Enhancing diagnostic performance of symptom-based criteria for irritable bowel syndrome by additional history and limited diagnostic evaluation. Am J Gastroenterol 111: 1446-1454, 2016

30. Armstrong D, Bennett JR, Blum AL, Dent J, De Dombal FT, Galmiche JP, Lundell L, Margulies M, Richter JE, Spechler SJ, et al: The endoscopic assessment of esophagitis: A progress report on observer agreement. Gastroenterology 111: 85-92, 1996.

31. Lundell LR, Dent J, Bennett JR, Blum AL, Armstrong D, Galmiche JP, Johnson F, Hongo M, Richter JE, Spechler SJ, et al: Endoscopic assessment of oesophagitis: Clinical and functional correlates and further validation of the Los Angeles classification. Gut 45: 172-180, 1999

32. Takashima T, Iwakiri R, Sakata Y, Yamaguchi D, Tsuruoka N, Akutagawa K, Komatsu-Tanaka M, Higuchi T, Tanaka Y, Shimoda R, et al: Endoscopic reflux esophagitis and Helicobacter pylori infection in young healthy Japanese volunteers. Digestion 86: 55-58, 2012.

33. Gyawali CP, Kahrilas PJ, Savarino E, Zerbib F, Mion F, Smout AJPM, Vaezi M, Sifrim D, Fox MR, Vela MF, et al: Modern diagnosis of GERD: The Lyon Consensus. Gut 67: $1351-1362,2018$

34. Gwee KA, Lu CL and Ghoshal UC: Epidemiology of irritable bowel syndrome in Asia: Something old, something new, something borrowed. J Gastroenterol Hepatol 24: 1601-1607, 2009.

35. Hoseini-Asl MK and Amra B: Prevalence of irritable bowe syndrome in Shahrekord, Iran. Indian J Gastroenterol 22: 215-216, 2003

36. Shah SS, Bhatia SJ and Mistry FP: Epidemiology of dyspepsia in the general population in Mumbai. Indian J Gastroenterol 20: 103-106, 2001.

37. Ghoshal UC, Abraham P, Bhatt C, Choudhuri G, Bhatia SJ, Shenoy KT, BankaNH, Bose K, Bohidar NP, Chakravartty K, et al: Epidemiological and clinical profile of irritable bowel syndrome in India: Report of the Indian Society of Gastroenterology Task Force. Indian J Gastroenterol 27: 22-28, 2008.

38. Han SH, Lee OY, Bae SC, Lee SH, Chang YK, Yang SY, Yoon BC Choi HS, Hahm JS, Lee MH, et al: Prevalence of irritable bowel syndrome in Korea: Population-based survey using the Rome II criteria. J Gastroenterol Hepatol 21: 1687-1692, 2006.

39. Kwan AC, Hu WH, Chan YK, Yeung YW, Lai TS and Yuen $\mathrm{H}$ Prevalence of irritable bowel syndrome in Hong Kong. J Gastroenterol Hepatol 17: 1180-1186, 2002.

40. Husain N, Chaudhry IB, Jafri F, Niaz SK, Tomenson B and Creed F: A population-based study of irritable bowel syndrome in a non-Western population. Neurogastroenterol Motil 20: 1022-1029, 2008.

41. Xiong LS, Chen MH, Chen HX, Xu AG, Wang WA and Hu PJ: A population-based epidemiologic study of irritable bowel syndrome in South China: Stratified randomized study by cluster sampling. Aliment Pharmacol Ther 19: 1217-1224, 2004.

42. Chang FY, Lu CL and Chen TS: The current prevalence of irritable bowel syndrome in Asia. J Neurogastroenterol Motil 16: $389-400,2010$
43. Karaman N, Türkay $\mathrm{C}$ and Yönem O: Irritable bowel syndrome prevalence in city center of Sivas. Turk J Gastroenterol 14: 128-131, 2003.

44. Celebi S, Acik Y, Deveci SE, Bahcecioglu IH, Ayar A, Demir A and Durukan P: Epidemiological features of irritable bowel syndrome in a Turkish urban society. J Gastroenterol Hepatol 19: 738-743, 2004

45. Masud MA, Hasan M and Khan AK: Irritable bowel syndrome in a rural community in Bangladesh: Prevalence, symptoms pattern, and health care seeking behavior. Am J Gastroenterol 96 : $1547-1552,2001$.

46. Quigley EM,Locke GR, Mueller-Lissner S, Paulo LG, Tytgat GN, Helfrich I and Schaefer E: Prevalence and management of abdominal cramping and pain: A multinational survey. Aliment Pharmacol Ther 24: 411-419, 2006.

47. Vandvik PO, Lydersen S and Farup PG: Prevalence, comorbidity and impact of irritable bowel syndrome in Norway. Scand $\mathbf{J}$ Gastroenterol 41: 650-656, 2006.

48. Drossman DA, Li Z, Andruzzi E, Temple RD, Talley NJ, Thompson WG, Whitehead WE, Janssens J, Funch-Jensen P, Corazziari E, et al: U.S. householder survey of functional gastrointestinal disorders. Prevalence, sociodemography, and health impact. Dig Dis Sci 38: 1569-1580, 1993.

49. Saito YA, Schoenfeld P and Locke GR III: The epidemiology of irritable bowel syndrome in North America: A systematic review. Am J Gastroenterol 97: 1910-1915, 2002.

50. Boekema PJ, van Dam van Isselt EF, Bots ML and Smout AJ: Functional bowel symptoms in a general Dutch population and associations with common stimulants. Neth J Med 59: 23-30, 2001.

51. Agréus L, Svärdsudd K, Nyrén O and Tibblin G: Irritable bowel syndrome and dyspepsia in the general population: Overlap and lack of stability over time. Gastroenterology 109: 671-680, 1995.

52. Hillilä MT and Färkkilä MA: Prevalence of irritable bowel syndrome according to different diagnostic criteria in a non-selected adult population. Aliment Pharmacol Ther 20: 339-345, 2004

53. Kay L, Jørgensen T and Jensen KH: The epidemiology of irritable bowel syndrome in a random population: Prevalence, incidence, natural history and risk factors. J Intern Med 236: 23-30, 1994.

54. Thompson WG, Irvine EJ, Pare P, Ferrazzi S and Rance L: Functional gastrointestinal disorders in Canada: first population-based survey using Rome II criteria with suggestions for improving the questionnaire. Dig Dis Sci 47: 225-235, 2002.

55. Boyce PM, Koloski NA and Talley NJ: Irritable bowel syndrome according to varying diagnostic criteria: Are the new Rome II criteria unnecessarily restrictive for research and practice? Am J Gastroenterol 95: 3176-3183, 2000.

56. Mearin F, Badia X, Balboa A, Baró E, Caldwell E, Cucala M, Díaz-Rubio M, Fueyo A, Ponce J, Roset M: Irritable bowel syndrome prevalence varies enormously depending on the employed diagnostic criteria: Comparison of Rome II versus previous criteria in a general population. Scand J Gastroenterol 36: 1155-1161, 2001.

57. El-Salhy M, Patcharatrakul T, Hatlebakk JG, Hausken T, Gilja $\mathrm{OH}$ and Gonlachanvit S: Chromogranin A cell density in the large intestine of Asian and European patients with irritable bowel syndrome. Scand J Gastroenterol 52: 691-697, 2017.

58. El-Salhy M, Patcharatrakul T, Hatlebakk JG, Hausken T, Gilja $\mathrm{OH}$ and Gonlachanvit S: Enteroendocrine, Musashi 1 and neurogenin 3 cells in the large intestine of Thai and Norwegian patients with irritable bowel syndrome. Scand J Gastroenterol 52: 1331-1339, 2017.

59. Whitehead WE and Drossman DA: Validation of symptom-based diagnostic criteria for irritable bowel syndrome: A critical review. Am J Gastroenterol 105: 814-820; quiz 813, 821, 2010.

60. Moayyedi P and Ford AC: Symptom-based diagnostic criteria for irritable bowel syndrome: The more things change, the more they stay the same. Gastroenterol Clin North Am 40: 87-103, 2011.

61. Palsson OS, Whitehead WE, van Tilburg MA, Chang L, Chey W, Crowell MD, Keefer L, Lembo AJ, Parkman HP, Rao SS, et al: Rome IV diagnostic questionnaires and tables for investigators and clinicians. Gastroenterology, Feb 13, 2016 (Epub ahead of print).

62. Sood R, Gracie DJ, Gold MJ, To N, Pinto-Sanchez MI, Bercik P, Moayyedi P, Ford AC and Law GR Derivation and validation of a diagnostic test for irritable bowel syndrome using latent class analysis. Aliment Pharmacol Ther 45: 824-832, 2017.

63. Kruis W, Thieme C, Weinzierl M, Schüssler P, Holl J and Paulus W: A diagnostic score for the irritable bowel syndrome. Its value in the exclusion of organic disease. Gastroenterology 87: 1-7, 1984. 
64. Fasano A, Berti I, Gerarduzzi T, Not T, Colletti RB, Drago S Elitsur Y, Green PH, Guandalini S, Hill ID, et al: Prevalence of celiac disease in at-risk and not-at-risk groups in the United States: A large multicenter study. Arch Intern Med 163: 286-292, 2003.

65. van der Wouden EJ, Nelis GF and Vecht J: Screening for coeliac disease in patients fulfilling the Rome II criteria for irritable bowel syndrome in a secondary care hospital in The Netherlands: A prospective observational study. Gut 56: 444-445, 2007.

66. Locke GR III, Murray JA, Zinsmeister AR, Melton LJ III and Talley NJ: Celiac disease serology in irritable bowel syndrome and dyspepsia: a population-based case-control study. Mayo Clin Proc 79: 476-482, 2004.

67. Hin H, Bird G, Fisher P, Mahy N and Jewell D: Coeliac disease in primary care: Case finding study. BMJ 318: 164-167, 1999.

68. Shahbazkhani B, Forootan M, Merat S, Akbari MR, Nasserimoghadam S, Vahedi H and Malekzadeh R: Coeliac disease presenting with symptoms of irritable bowel syndrome. Aliment Pharmacol Ther 18: 231-235, 2003.

69. Catassi C, Kryszak D, Louis-Jacques O, Duerksen DR, Hill I, Crowe SE, Brown AR, Procaccini NJ, Wonderly BA, Hartley $\mathrm{P}$, et al: Detection of Celiac disease in primary care: A multicenter case-finding study in North America. Am J Gastroenterol 102: 1454-1460, 2007.

70. Sanders DS, Carter MJ, Hurlstone DP, Pearce A, Ward AM, McAlindon ME and Lobo AJ: Association of adult coeliac disease with irritable bowel syndrome: A case-control study in patients fulfilling Rome II criteria referred to secondary care. Lancet 358: 1504-1508, 2001

71. Korkut E, Bektas M, Oztas E, Kurt M, Cetinkaya H and Ozden A The prevalence of celiac disease in patients fulfilling Rome III criteria for irritable bowel syndrome. Eur J Intern Med 21: 389-392, 2010

72. Sanders DS, Patel D, Stephenson TJ, Ward AM, McCloskey EV, Hadjivassiliou M and Lobo AJ: A primary care cross-sectiona study of undiagnosed adult coeliac disease. Eur J Gastroenterol Hepatol 15: 407-413, 2003.

73. El-Salhy M, Lomholt-Beck B and Gundersen D: The prevalence of celiac disease in patients with irritable bowel syndrome. Mol Med Report 4: 403-405, 2011.

74. Aziz I and Sanders DS: The irritable bowel syndrome-celiac disease connection. Gastrointest Endosc Clin N Am 22: 623-637, 2012.

75. Cash BD, Rubenstein JH, Young PE, Gentry A, Nojkov B, Lee D, Andrews AH, Dobhan R and Chey WD: The prevalence of celiac disease among patients with nonconstipated irritable bowel syndrome is similar to controls. Gastroenterology 141: 1187-1193, 2011.

76. Isgar B, Harman M, Kaye MD and Whorwell PJ: Symptoms of irritable bowel syndrome in ulcerative colitis in remission. Gut 24: 190-192, 1983.
77. El-Salhy M, Gundersen D, Gilja OH, Hatlebakk JG and Hausken T: Is irritable bowel syndrome an organic disorder? World J Gastroenterol 20: 384-400, 2014.

78. Ansari R, Attari F, Razjouyan H, Etemadi A, Amjadi H, Merat S and Malekzadeh R: Ulcerative colitis and irritable bowel syndrome: Relationships with quality of life. Eur J Gastroenterol Hepatol 20: 46-50, 2008.

79. Simrén M, Axelsson J, Gillberg R, Abrahamsson H, Svedlund J and Björnsson ES: Quality of life in inflammatory bowel disease in remission: The impact of IBS-like symptoms and associated psychological factors. Am J Gastroenterol 97: 389-396, 2002.

80. Keohane J, O'Mahony C, O'Mahony L, O'Mahony S, Quigley EM and Shanahan F: Irritable bowel syndrome-type symptoms in patients with inflammatory bowel disease: A real association or reflection of occult inflammation? Am J Gastroenterol 105: 1788, 1789-1794; quiz 1795, 2010.

81. Minderhoud IM, Oldenburg B, Wismeijer JA, van Berge Henegouwen GP and Smout AJ: IBS-like symptoms in patients with inflammatory bowel disease in remission; relationships with quality of life and coping behavior. Dig Dis Sci 49: 469-474, 2004.

82. El-Salhy M, Halwe J, Lomholt-Beck B and Gundersen D: The prevalence of inflammatory bowel diseases, microscopic colitis, and colorectal cancer in patients with irritable bowel syndrome. Gastroenterol Insights 3: e3, 2011.

83. Tolliver BA, Herrera JL and DiPalma JA: Evaluation of patients who meet clinical criteria for irritable bowel syndrome. Am J Gastroenterol 89: 176-178, 1994.

84. Spiller R, Aziz Q, Creed F, Emmanuel A, Houghton L, Hungin P, Jones R, Kumar D, Rubin G, Trudgill N, et al: Guidelines on the irritable bowel syndrome: Mechanisms and practical management. Gut 56: 1770-1798, 2007.

85. El-Salhy M, Hatlebakk JG, Gilja OH and Hausken T: The relation between celiac disease, nonceliac gluten sensitivity and irritable bowel syndrome. Nutr J 14: 92, 2015.

86. Heizer WD, Southern S and McGovern S: The role of diet in symptoms of irritable bowel syndrome in adults: A narrative review. J Am Diet Assoc 109: 1204-1214, 2009.

87. O'Sullivan MA, Mahmud N, Kelleher DP, Lovett E and O'Morain CA: Patient knowledge and educational needs in irritable bowel syndrome. Eur J Gastroenterol Hepatol 12: 39-43, 2000.

88. Stenner PH, Dancey CP and Watts S: The understanding of their illness amongst people with irritable bowel syndrome: A Q methodological study. Soc Sci Med 51: 439-452, 2000.

This work is licensed under a Creative Commons Attribution-NonCommercial-NoDerivatives 4.0 International (CC BY-NC-ND 4.0) License. 